\title{
La "cédula real de los Amaycha". Contextualización, análisis y transcripción de un documento controversial
}

The "Amaychas's Royal Decree" Contextualization, analysis and transcription of a controversial document

\section{Jorge Sosa}

\section{(2) OpenEdition \\ Journals}

\section{Electronic version}

URL: http://journals.openedition.org/corpusarchivos/1374

DOI: 10.4000/corpusarchivos. 1374

ISSN: 1853-8037

\section{Publisher}

Diego Escolar

\section{Electronic reference}

Jorge Sosa, "La "cédula real de los Amaycha". Contextualización, análisis y transcripción de un documento controversial », Corpus [En línea], Vol 5, No 1 | 2015, Publicado el 16 julio 2015, consultado el 10 diciembre 2020. URL : http://journals.openedition.org/corpusarchivos/1374 ; DOI : https:// doi.org/10.4000/corpusarchivos.1374

This text was automatically generated on 10 December 2020 .

Licencia Creative Commons: Atribución-NoComercial 2.5 Argentina (CC BY-NC 2.5 AR) 


\title{
La "cédula real de los Amaycha". Contextualización, análisis y transcripción de un documento controversial
}

\author{
The "Amaychas's Royal Decree" Contextualization, analysis and transcription of \\ a controversial document
}

Jorge Sosa

\section{EDITOR'S NOTE}

Fecha de recepción del original: 07/04/2014

Fecha de aceptación para publicación: 15/12/2014

\section{Introducción y objetivos}

“Al Sr. Juez de Primera Instancia.

Juan Solis Ovando en las diligencias que ha iniciado

contra Don Filemon Palavecino sobre entrega de

la cédula real de los indios de Amaicha, y la

protocolizacion de la expresada cédula,

ante su señoría como mejor prueba expongo: "1

1 En el contexto de mi investigación doctoral ${ }^{2}$ hube de enfrentarme con lo que comúnmente se conoce como la "Cédula Real de los amaichas" con la intención de georreferenciar la misma, es decir poder hacer un mapa del territorio cedido a los "amaichas"3.

2 Tratar con documentos antiguos suele representar un dolor de cabeza por distintas razones, pero en el caso de esta "cédula" el problema parecía zanjado ya que el texto de 
este documento había salido a la luz tempranamente de la mano de investigaciones folclóricas (Carrizo 1937, Cano Vélez 1943, Reyes Gajardo 1966) y sociológicas (Román y Mullet 1949, Isla 2002). Sin embargo, a poco sondear estas versiones de la cédula, noté ciertas deficiencias -algunas de las cuales se podrían deber al problema que genera toda copia de copia- que me llevaron a sospechar de la confiabilidad de estas versiones para entender el contenido de la cédula ${ }^{4}$. No quedaba más remedio entonces que recurrir al documento "original” y hacer una transcripción, pero ¿cuál original?

3 Si bien desde un principio sabía que esta búsqueda estaba condenada al fracaso (ya varios investigadores pasaron por archivos nacionales e internacionales buscando la cédula de 1716), con probar nada se perdía, y, por el camino, seguro aparecerían otros materiales de interés. En base a una nota de Reyes Gajardo (1966, p. 53), a la lectura de dos folletos (uno impreso y hecho por Amaicha en 1996 y otro más rústico hecho en base a fotocopias por parte de Quilmes en 1998), en donde supuestamente se reproducía la "Cédula Real", más los datos aportados por Lorena Rodríguez $z^{5}$ y los del "Ingeniero Medina" ${ }^{\circ}$, finalmente di con el Protocolo 36 (Figura 1), que contiene la protocolización de la "cédula". Si bien nunca di con la cédula original, trabajar con el material de la protocolización permitió confirmar que tratar con documentos antiguos representa siempre una oportunidad de descubrir pistas encadenadas que llevan a re-interpretar lo que parecía ya fundado y replantearse los problemas originales de investigación.

En este cas, el título mismo con que es mencionado el texto ("cédula de los Amaichas") comenzaba a ser cuestionado por la misma "cédula", ya que el documento a tratar es una copia de una merced de tierras hecha a favor no solo de los amaichas, sino de un conjunto de pueblos: los "Pueblos del Bañado de Quilmes, San Francisco, Tio Punco, Encalilla y Amaicha", en la persona de quien sería el cacique de todos esos "pueblos", por entonces "Don Francisco Chapurfe". Evidentemente se trataba de un texto más complejo de lo que en un principio podía parecer, y a la vez controversial. Tempranamente, Reyes Gajardo (1966) había señalado puntos de no concordancia entre los personajes mencionados y las cronologías implícitas, y la dificultad de entender idiomática y geográficamente ciertos pasajes del texto. En base a estas dificultades y discordancias se ha llegado a plantear la imposibilidad de entender el texto y no ha faltado incluso quien sospechara de la autenticidad del mismo.

En base a estas primeras consideraciones, los objetivos que nos propusimos desarrollar aquí son: a) ofrecer una transcripción textual de la "cédula", b) hacer una comparación con las versiones históricas conocidas y analizarlas, y c) discutir sobre ciertos acontecimientos del contexto histórico inmediato previo (1872-1892) al que se llevó a cabo la protocolización de la cédula, que pueden ser considerados claves para la consecución de la misma. Evidentemente queda como trabajo pendiente tanto un análisis diplomático del documento (actualmente en curso) y el análisis integral del contenido del mismo, que dada su extensión reservamos para otra oportunidad ${ }^{7}$. Por ello, a pesar del gran abanico de temas conexos que abre la discusión del texto cedulario, pero por razones lógicas de adecuación al espacio y temática de esta sección de Registros, aquí no se hablará de oralidad, ni de etnogénesis, ni simbolismo, etc., no por desconocerlos o restarles importancia (ver Sosa y Lenton, 2009), sino porque dada la complejidad de su manejo, los mismos son abordados en la tesis de doctorado ${ }^{8}$. 


\section{Qué es qué}

6 Antes de pasar al tema principal, es necesario hacer ciertas precisiones respecto al documento que se presentará y definir de qué se estará hablando cuando se mencionen términos como "cédula", "original", "copias" y "transcripción".

7 Si bien el texto es conocido ampliamente como "Cédula Real", la lectura del documento permite establecer la categoría de intervinientes y el asunto que se trata: oficiales españoles ratificando una donación de tierras; por lo que podemos afirmar que el texto corresponde a una merced de tierras antes que a una Real Cédula ya que esta, como señala Real Díaz (1970, p. 225) era "un documento eminentemente dispositivo y se convierte en el vehículo normal de relación entre el rey y las autoridades indianas. Encierra generalmente un precepto de gobernación".

El documento, según se lee, se trataría de un testimonio de una merced de tierra, hecho en Buenos Aires durante el siglo XVIII". Los testimonios o traslados son un tipo de “ copia autorizada en que además del documento reproducido se añade cierta fórmula que acredita su autenticidad como tal copia, y la reviste de la fe pública". Están validadas con la fe notarial "la cual le hace suplir con toda su fuerza jurídica al original" (Real Díaz 1970, pp. 30-38).

9 Establecida esta diferenciación, podemos decir que el documento que analizaremos es un Testimonio fechado en 1753 y por lo tanto sería el documento escrito más antiguo conocido hasta el momento en donde se refiere el texto que años más tarde se difundiría bajo el rótulo de "la cédula real". Es en base a este reconocimiento de preexistencia cronológica documental que nos referiremos a él como original, aun cuando el verdadero "original" sería el documento cedulario que hasta ahora no ha sido encontrado, ya sea por estar perdido, destruido o traspapelado ${ }^{10}$.

Como se verá en detalle luego, en 1892, por pedido del representante de los amaichas, se realizó la protocolización del testimonio. La protocolización es un procedimiento administrativo mediante el cual se incorpora un documento al libro de protocolos, el cual no es otra cosa que una colección de documentos que reúnen ciertas características reguladas por ley (en este caso, escrituras de Gobierno de Tucumán), ordenados cronológicamente, encuadernados y numerados correlativamente. Dichos documentos suelen denominarse matrices por ser a los que se recurre en caso de necesitar copias para distintos procesos legales. La importancia del acto de protocolización de un documento radica en que tiene como efecto directo dar certeza y constancia ante terceros sobre la existencia y legalidad del documento. En el caso que nos ocupa, el proceso de protocolización para lo cual se hace una escritura, prácticamente convirtió al testimonio en un documento indubitable.

11 Habiendo quedado el testimonio incorporado al acto protocolar, el representante de los amaichas solicitó se le hiciese copia del mismo y de la escritura de protocolización, las cuales le fueron hechas en papel timbrado. Dichas copias fueron a manos de la comunidad, concretamente a las del entonces cacique Timoteo Ayala, y son las que sirvieron muchos años después para ilustrar los folletos a los que hicimos referencia previamente. En base a esto y a ciertos detalles del texto de la "cédula", proponemos que estas copias otorgadas por el gobierno de Tucumán a la comunidad a través de su representante fueron el origen de las posteriores transcripciones aparecidas en trabajos académicos. Si bien aún debemos plantear esto a modo de hipótesis, creemos haber 
identificado así la fuente que originó una tradición de copias de copias o versiones, generando (en algunos casos por errores en la copia) una información distorsionada que, al ser retomada por autores posteriores que confiaron en su fuente, generó errores de interpretación. Una de las formas de guardar este tesoro enviado por el gobierno ha de haber sido su ocultamiento físico, y otro paralelo parece haber sido su memorización ${ }^{11}$, lo cual colaboró para crear un halo de misterio en torno a la "cédula real"12.

\section{Presentación de la fuente}

El documento que aquí se presenta forma parte del acervo del Archivo Histórico de Tucumán ${ }^{13} \mathrm{y}$ se encuentra inserto en un tomo correspondiente a la Sección Protocolos ${ }^{14}$, Protocolo 36, Tomo 3으, Serie C, año 1892, folio 1417 (r/v). El tomo ingresó al AHT desde el Archivo Intermedio, el día 7 de octubre de 2011, y fue fotografiado el 5 de octubre de 2012. El documento se compone de un folio (recto y verso) de papel sellado con el precio determinado por la ley del timbre. De aspecto amarronado, se encuentra en estado regular de conservación, mostrando bordes rotos, una rajadura en sentido horizontal que atraviesa y casi corta por la mitad al documento, y manchas residuales de pegamento de cinta adhesiva transparente (dispuestas vertical y horizontalmente) colocada con mucha anterioridad al ingreso del Protocolo al AHT.

La letra utilizada es cursiva, compacta y sin ornamentaciones, sin embargo el trazo de los caracteres revela cierta sobrecarga de tinta que con el tiempo transcurrido se convirtieron en manchas que en algunos casos, como el fin de palabras con vocales, dificulta su lectura. La estructura del texto es en bloque, sin tabulaciones y con márgenes ajustados. En el recto, el margen izquierdo es de aproximadamente $2 \mathrm{~cm}$, mientras que el derecho es el mínimo, estando afectada ese lado de la hoja por un proceso de destrucción del borde (ver Figura 2), el margen inferior es de aproximadamente 1,5 cm. En el verso el margen superior es de unos $2 \mathrm{~cm}$, mientras que el izquierdo y derecho son los mínimos hasta pasada la mitad de la foja a partir de la cual se deja un margen de unos $2 \mathrm{~cm}$.

La tinta ${ }^{15}$ presenta cierta decoloración hacia un tono café, no presenta halos pero sí claras evidencias de transminado o migración (que a veces entorpecen la lectura del texto), con escasas afectaciones mecánicas (perforado) sobre el papel. Las características generales señaladas apuntan a que se trata de una tinta ferrogálica, desbalanceada tipo II (Odor Chávez 2009). Solo análisis no destructivos mediante tiras reactivas u otros más avanzados como los planteados por Mendoza Cuevas et al. (2009) permitirían conocer mayores detalles sobre la tinta.

Los folios fueron fotografiados usando una cámara compacta Sony, con una resolución de 3167 x 4828 píxeles, lo cual permitió trabajar con ampliaciones sin cuadriculaciones.

El documento fue transcripto literalmente, siguiendo las Normas de Edición y Transcripción de los Documentos sugeridas por Corpus ${ }^{16}$, publicación electrónica dependiente de la Facultad de Humanidades y Ciencias de la Educación de la Universidad de la República de Uruguay. Estas normas, más modernas y con algunas diferencias respecto de las Normas para la Transcripción de Documentos Históricos Hispanoamericanos de 1961(Ver PRIA 1974 y Tanodi 1992), más frecuentemente usadas, ha sido preferida por cuanto minimizan la intervención del transcriptor, alientan las transcripciones que respetan la ortografía original y desalientan las normalizaciones 
modernas del texto. Por otra parte las normas de 1957 y 1961, si bien gozan de un uso más amplio localmente, han sido cuestionadas casi desde el comienzo de las mismas (Garcés 1961), y hasta se ha propuesto que "la posible sustantividad de las normas de transcripción parece que debería exigir un anticuado objetivo" (García Lagarreta 1979, p. 182), ya que como formuló Floriano Cumbreño

El criterio para la realización de las transcripciones dista mucho de estar unificado. La causa de ello es bien conocida: cada uno transcribe los documentos con arreglo a los fines que se propone llevar a cabo con su transcripción, y como estos fines son muy diversos, claro es que los procedimientos de transcripción habrán de ser por completo diferentes. (1946, p. 99)

Si bien, como señalaba López Villalba (1998), parecería una paradoja encontrar múltiples normas contraviniendo así la esencia misma del término norma, recientes trabajos modernos de otras latitudes muestran también esta necesidad de flexibilidad y adecuación al material particular que se trabaje, sin que por ello no se tome en cuenta lo ya formulado o se incurra en una anarquía que imposibilite compartir método y resultados (Romero Andonegi 2006). De hecho, las mismas Normas de transcripción y edición de textos y documentos del C.S.I.C. de 1944, se presentaban a sí mismas "más bien como consejos y recomendaciones que como reglas rígidas e inalterables" (p. 3).

Entendemos que por el tipo de contenido del documento (en donde abundan toponimias, gentilicios y expresiones anacrónicas) era menester tratar de mostrar el mismo de manera cruda, para comparar el material resultante con las versiones modernas que se conocen del mismo. De esta manera el rol del transcriptor se limita a limpiar visualmente el documento de origen, sin intervenir, en primera instancia, con el significado de los grafemas. Por otra parte encontramos sumamente útil la propuesta de las Normas de Corpus, respecto a la numeración de los renglones ya que facilita la tarea de verificación de los eventuales lectores. Por último, mantener el estilo de expresión utilizado por el escribiente del documento puede ser útil para objetivos de análisis distintos a los seguidos en este artículo.

Si bien en el documento analizado la letra utilizada corresponde a una bastardilla (sensu Tanodi 1992), para algunas partes de su interpretación se recurrió a la consulta de algunos manuales de paleografía y abreviaturas (Silva Prada 2001, Tanodi 2001, Carlin 2003), aunque con escasos resultados.

21 El documento se estructura siguiendo el formato de las mercedes de tierra, en donde el escribano interviniente nombra a los actuantes, el lugar geográfico en donde se realiza la merced, algún ritual asociado a la posesión de la tierra, acto de fe y cierre.

\section{El contexto documental}

El documento que nos ocupa es el puesto como cabecera de un oficio que va desde la foja 1417 hasta la 1426, aunque podría llegar a hablarse de 3 documentos:

a) el Testimonio de 1753 que ocupa la foja 1417 (r-v);

b) los antecedentes, contingencias y pasos seguidos para lograr la protocolización, que van de las fojas 1418 (r) a 1426 (r); y

c) la escritura de protocolización en la foja 1427 a 1428 (r). 
No obstante esta división, solamente el análisis del contenido de las tres partes permite tener una idea completa de la significancia de este proceso.

Según se lee en los antecedentes, existe una demanda interpuesta contra Don Filemón Palavecino, sobre "exhibición de una cédula real". El representante de los "indios de la comunidad de Amaichas y Colalao", el Sr. Juan Solís Ovando, manifiesta mediante nota del 30 de junio de 1892 la necesidad de protocolizar la "cédula" que expone y que se le dé copia, por ser esta "muy antigua y de mucha importancia de los intereses" que representa. Con algunos escollos menores, finalmente la "cédula" exhibida es protocolizada el 30 de noviembre de 1892 mediante Escritura número 582, fojas 1427 y 1428, por el escribano de gobierno Maximio (sic) Sánchez. En la misma se hace referencia a la relación entre esta escritura y los juicios que Sigifredo Brachieri tenía iniciados contra los amaichas, de los que Ovando solicita ser parte representante. Finalmente el 7 de diciembre de 1892, se le entregan a Ovando las copias de la escritura, de la cédula y demás escritos, para que "surjan los efectos que en derecho haya lugar".

Esta protocolización prácticamente significó el cierre de un largo pleito iniciado en 1796 a través de una demanda interpuesta por el "juez y cacique" del pueblo de los amaichas, don Lorenzo Olivares, contra Nicolás Aramburu (vecino de Cafayate, provincia de Salta). Este pleito, que ha sido ya trabajado en detalle por Rodríguez (2009) se prolongó durante todo el siglo XIX, cambiando (por razones de fallecimientos y herencias) de representantes en ambos bandos y matizado por una serie de avances y retrocesos a favor de unos u otros litigantes; pero tuvo un punto de inflexión en 1872, cuando el gobierno de Tucumán dictó una sentencia a favor de Brachieri ${ }^{17}$.

El 30 de junio de $1872^{18}$ "Balentin Armella", por entonces comandante militar del departamento de Encalilla ${ }^{19}$, envía desde Colalao (donde residía) una carta al ministro de gobierno Eudoro Avellaneda ${ }^{20}$. Gracias a esta nos enteramos que el gobierno de la provincia había ordenado se le dieran en posesión a Brachieri los terrenos en litigio, lo cual se vio frustrado por el "motín" de los amaichas. El motín, como lo denomina Armella en su carta, no pasa a mayores, pero la decisión del gobierno, que contraría las sentencias de primera y segunda instancia del año $1850^{21}$ y 1858 , provoca que un vecino de Encalilla, Juan Pablo Pastrana, haga un viaje hasta Buenos Aires, para buscar el expediente que a fines del siglo XVIII había tramitado Olivares ante la Audiencia. Al no encontrar dicha documentación, Pastrana presenta una carta el 28 de septiembre de 1872 al Poder Ejecutivo Nacional para obtener ayuda, con la suerte (?) de que en ese momento el ministro de Justicia, Culto e Instrucción Pública de la Nación, Nicolás Avellaneda (hermano de Eudoro), también ostentaba el cargo de Ministro de Interior ${ }^{22}$. Como sostiene Herrera (2009, p. 3), este era uno de los ministerios más importantes por sus funciones de "agencia de desarrollo" y a través del cual el gobierno de Tucumán obtuvo numerosos favores del gobierno nacional. Como sabemos, quien se hallaba en la presidencia en ese momento era Domingo Sarmiento, quien no se caracterizaba justamente por su simpatía hacia las poblaciones indígenas. Es de presumir que el asunto que proponía Pastrana fue tratado sólo por Avellaneda, ya que es el Departamento de Justicia el que se encarga de transcribir la carta y responderle a Pastrana. Las transcripciones de la carta y la respuesta fueron enviadas al gobierno de Tucumán el $1^{\circ}$ de octubre de 1872 . De la respuesta entregada a Pastrana se rescata que el Departamento de Justicia aclara que el Poder Ejecutivo Nacional no podía interferir en cuestiones administrativas propias de la provincia, pero que con esta nota se dirigía al gobierno de Tucumán "recomendando a su equidad este asunto, a fin de que haga lo 
que sea legalmente posible en su favor"23. Si bien parece una contestación de rutina, las tres últimas palabras "en su favor" son todo un guiño a favor de los intereses de los indios de Amaicha. Y para que quede clara cuál era la visión que se tenía del conflicto el día 2 de octubre, el mismo Nicolás Avellaneda envía una carta en papel sellado de su propio ministerio al gobernador de Tucumán, Federico Helguera, de cuyo contenido se desprende que el ministro había tenido oportunidad de obtener más detalles que los expresados en la propia carta de Pastrana, por lo que no sería raro que este hubiese tenido la oportunidad de hablar personalmente con el ministro ${ }^{24}$.

La suerte de 300 familias indígenas que ocupan terrenos poblados por sus abuelos, y

a lo que tienen vinculados sus afecciones, sus intereses y sus tradiciones, no puede ser indiferente.

Si ofrecemos nuestro suelo con anhelo al extrangero, si fomentamos la formación de colonias ¿cómo no mirar con interés esos grupos de poblaciones pacíficas y laboriosas que la mano del tiempo ha arraigado en medio de nuestro campo?

Aparte de estas consideraciones de equidad, hay otras de distinto género que no escaparán a la ilustración de V.E.

Así el PEN ha creído que debía interesar a VE en su favor, pidiéndole que por los medios legales que repute conveniente, acoja y favorezca a los peticionarios. ${ }^{25}$

Si bien el texto da lugar a numerosas reflexiones, solo me limitaré a señalar aquellas específicas al tema. ¿De dónde obtiene el número de 300 familias? El censo de población de septiembre de 1869 nos informa de 1439 habitantes pero no señala número de familias.

31 En primer lugar es remarcable el hecho de la premura con que fue tratado todo. El "motín de Amaicha" fue el 30 de junio, Pastrana viaja y el 30 de septiembre presenta la carta, al día siguiente tiene respuesta del gobierno y, al otro, Avellaneda escribe su recomendación. ¿Cuáles son los resortes que supo o pudo activar Pastrana para recibir esta atención?

en la defensa que hace por los peticionarios, Avellaneda apela no solo al aspecto económico de la ocupación del terreno ("sus intereses") que es el tema que se explicita siempre en los oficios judiciales de los pleitos, sino a cuestiones humanísticas como los afectos y la tradición, introduciendo así en el área discursiva elementos que en el futuro formarían parte del discurso indígena a la hora de plantear la defensa de un territorio ${ }^{26}$.

Llama la atención también como posiciona Avellaneda (quien 4 años después promoverá la sanción de la Ley de Inmigración) a los amaichas, al colocarlos en un plano opuesto a lo extranjero, y cuidándose de considerarlos un grupo distinto a una colonia. Por otra parte, a pesar de las advertencias de Armella (el motín de Amaicha), Avellaneda los califica como pacíficos y laboriosos ${ }^{27}$. Esta imagen de los "indígenas" de Amaicha es fundamental a la hora de prestar su apoyo al pedido, lo cual contrasta con la visión que expresará pocos años más tarde (1878) al hablar de los "indios de la Pampa"28.

Si bien el final de la carta es contundente (dice el Presidente que por la forma que pueda favorezca a los peticionarios), en el párrafo anterior queda suspendida una sugerencia más que intrigante y creo que aún es necesario trabajar para encontrar su clave, ¿cuáles son las otras consideraciones "de distinto género" que el gobernador conoce y que Avellaneda le recuerda al oído para que no podamos escuchar? ${ }^{29}$

En contraste con la premura demostrada por el gobierno nacional en tratar el asunto, el provincial acusa recibo de la carta de Avellaneda recién el 21 de noviembre. Sin 
embargo los problemas entre los amaichas y Brachieri parecen haber entrado en un impasse, o al menos los archivos no muestran nuevos movimientos al respecto sino hasta el 20 de diciembre de 1883 cuando el Supremo Tribunal de Justicia publica una lista de las causas seguidas por él entre las que se cuenta, en la categoría de "En revisión", la de "Los indios de Amaicha, Encalilla y Colalao, con los herederos de Sigisfredo Brachieri, sobre la posesión de unas tierras" (El Orden , 20/12/1883, p. 1 col. 6).

36 Sin embargo lo que sí se nota en ese período (1872-1883) es un cambio a favor del representante de los amaichas y el estatus de estos, ya que a partir del 29 de julio de 1881, a través de una carta del ministro Sisto Terán, Pastrana es nombrado "Capitán y representante general de la Comunidad de Amaycha" ${ }^{30}$, y pocos meses después aparece ya nombrado como "juez de paz" ${ }^{31}$. Así, Pastrana pasa a ostentar un prestigio que lo distingue de los anteriores "representantes" y a su vez el colectivo "indios" retoma la designación de "comunidad", que si bien había sido utilizada en documentos de $1845^{32}$, a posteriori había sido abandonada. La reintroducción del colectivo comunidad, aun cuando por unos años más convivió con el de "indios de", me parece sumamente interesante por cuanto es esta categoría la que se usará luego para interactuar con el Estado, y sobre la que se montó y recreó a través de los estudios folclóricos de fines del XIX y principios de XX (Quiroga 1992 [1929], Carrizo 1937) una imagen romántica de los habitantes de esa zona.

Respecto a la nueva investidura de Pastrana, su período duró poco ya que en octubre de 1882 es destituido de los cargos de juez de paz y comisario por quejas de los vecinos que lo acusan de abuso de autoridad. Esta clase de superposiciones de funciones, quejas y destituciones era algo frecuente (no solo en la campaña tucumana ${ }^{33}$ ), y público ${ }^{34}$, de modo tal que los que le precedieron ${ }^{35} \mathrm{y}$ los que le sucedieron ${ }^{36}$ cayeron bajo la misma vara $^{37}$. De todos modos, gracias a ese viaje fue recompensado con las tierras de El Paraíso (en donde hoy viven sus descendientes), y el lustre del "patriarca" Pastrana ha trascendido en el tiempo gracias a los relatos que aún se transmiten oralmente de él ${ }^{38}$. Ahora bien, desde el estado de "en revisión" de 1883 hasta la protocolización de 1892 hay un período de 9 años, que puede o no ser demasiado tiempo para sostener un estado de equilibrio, pero que sin lugar a dudas aún es un vacío que requiere trabajo de archivo si se quiere llegar a explicar: ¿cómo se sostuvo este impasse?, ¿cómo y por qué aparece esta cédula en 1892?, ¿quién y cómo consiguió la cédula?, ¿quién era Juan Ovando $^{39}$ y por qué aparece representando a los "indios de la Comunidad de amaicha"?

Para ir cerrando, existe una pregunta que aunque parezca obvia, no es menor: ¿por qué con la protocolización de la cédula se terminó con un conflicto que había demostrado ser tan persistente que superó generaciones de contrincantes (desde Aramburu hasta Brachieri, desde Olivares hasta Ovando), sistemas políticos y revoluciones (desde la Colonia a la República pasando por una revolución y guerras civiles)? Creo que gran parte de la respuesta está relacionada con cambios macro en el sistema económico de la zona.

Si bien la zona vallista durante el período colonial y de transición al republicano habían resultado ser un ámbito de gran tránsito y de engorde de ganado gracias al comercio con las minas de Bolivia y Chile (Bazán 1987, Conti y Sica 2011), la re-estructuración política del territorio (y con ella la de fronteras) y la apertura de nuevas rutas por el llano (Santamarina 1945) dejó a esta zona apartada del circuito comercial provincial. Hacia fines del siglo XIX las cosas habían cambiado para mal como consecuencia de las 
nuevas políticas de aduanas de Chile, Bolivia y Perú en donde se colocaba el ganado ${ }^{40}$, a lo cual se sumaban los efectos negativos de heladas, granizos y sequías en años sucesivos, algunas epidemias y emigración de la mano de obra local atraída por el auge de los ingenios azucareros en Tucumán y Salta (Meister et al. 1963, pp. 31-32). Demográficamente las cosas han cambiado; si el censo de 1862 arrojaba para la zona de Encalilla-Amaicha 1439 habitantes, para 1895 arroja 767 habitantes ${ }^{41}$.

41 Paralelamente a esto, y fruto de la transformación económica y el régimen de propiedad de la tierra latifundista en la zona salteña del valle, en Cafayate (de donde era el litigante original Aramburu) la industria de la vid ya se estaba desarrollando y sacaba su producción a través de Salta. Es decir que hacia el año de protocolización de la cédula, la zona que había sido el escenario de la larga disputa, aparentemente había perdido su razón de ser. Si a esto le sumamos la información histórica (Carrizo 1937, Cano Vélez 1943, Bruno 1976, Rodríguez Espada 1984) referida al éxodo de la población de Encalilla a partir de 1884 debido a la falta de agua, tal vez podamos decir que nos quedamos sin elementos que justifiquen seguir el pleito.

Por último, recordando la sugerencia del ministro Avellaneda al gobernador Helguera en 1872, cabe preguntarse ¿qué motivos podía tener el gobierno tucumano para apoyar a los amaichas en sus reclamos? A modo de hipótesis ${ }^{42}$, es posible plantear que los problemas de jurisdicción heredados de la época colonial tenían aún tanta vigencia como la habían tenido a mediados del XVII con la creación de la ciudad de San Fernando del Valle de Catamarca, y que por ello resultaba conveniente hacer acto de presencia en la zona. El fin de las luchas civiles, permitió que los viejos conflictos territoriales entre las provincias de Catamarca, Tucumán y Salta volvieran a ser una cuestión a tratar, por lo que tempranamente, en1862 Tucumán se encargó de formar unilateralmente una comisión para el estudio de los "Límites de la Provincia" (Gobierno de Tucumán 1916, p. 64) con la intención de llegar a generar un mapa de sus límites. La población más importante del Valle, Santa María, si bien respondía políticamente a Catamarca, en términos prácticos se relacionaba con Tucumán a punto tal de llegar a plantearse la posibilidad de anexión "pacífica" del departamento de Santa María a la provincia de Tucumán ${ }^{43}$, a diferencia de la que ya había sucedido en diciembre de 1835 bajo el gobierno de Heredia (Zavalía 2003, p. 170) ${ }^{44}$. Esta conflictividad entre Tucumán y Catamarca, sumada a cierta desconfianza hacia el comandante Armella (quien tenía lazos comerciales con Salta) promovió que el representante de los amaicha, Pastrana, fuese nombrado en 1881 "Capitán" por el gobernador de Tucumán, y que cuidase las fronteras por "la parte de Santa María" 45 .

No podemos explayarnos más sobre el tema, pero queremos cerrar esta sección notando que los pedimentos mineros en el Aconquija que existen en los archivos históricos de Tucumán y Catamarca, demuestran que los sueños de oro y plata que habían motivado a los españoles del XVI y XVII aún estaban vivos en las autoridades tucumanas y catamarqueñas, y tal vez explican en parte la conflictividad respecto a los límites y el compromiso por parte de Tucumán para apoyar argumentos que estuvieran a favor de sus pretensiones.

\section{La "Cédula Real" en el siglo XX}

Hasta no hace mucho, la versión más antigua que se conocía de la cédula era la que publicara Carrizo (1937), la cual, según comenta en su libro, “algunas personas de la 
localidad saben de memoria" (p. 35) y le fuera dictada por el maestro Ramón Cano Vélez ${ }^{46}$. Algo a remarcar en esta obra es la apreciación respecto a la extensión de los "dominios" de los amaichas, ya que sostiene que esta cédula seguramente los "agrandaba", y que si bien no da los límites territoriales prehispánicos "es de creer que los límites de esta merced reproduzcan en gran parte el de sus dominios anteriores..." (p. 36). El mismo Cano Vélez años más tarde en su libro Amaicha (1946) aclara que el texto que reproduce lo obtuvo de "una copia de la CEDULA REAL, que obra en poder de un vecino" (p. 22), es decir que su fuente de información es escrita y no oral.

La siguiente mención de la cédula sería la de Román y Mullet (1949), quienes la publican en forma de apéndice bajo la designación de "Título originario de la Comunidad de Amaicha del Valle" (p. 47), y si bien no especifican la fuente, el texto es exactamente el mismo que el de Cano Vélez.

La única diferencia entre estos tres primeros textos es que Carrizo no incluyó la presentación que hace el escribano de Buenos Aires, y que entre los firmantes de la cédula, Carrizo escribió "Nievas" mientras que Cano Vélez escribió "Nievar", lo cual fue copiado por Román y Mulet pero con un error de cambio de una letra, "Neivar" en lugar de "Nievar".

Posteriormente, Reyes Gajardo (1966) también reproduce el texto citando como fuente la versión de Román y Mullet, pero agrega como al pasar que "el texto de Cédula real de la Comunidad de Amaicha ya transcripto por varios autores, que lo han tomado de una copia,...". Páginas más adelante llamativamente agrega a su fuente una nota que remite a la copia existente en el Archivo Histórico de Tucumán (aun cuando Román y Mullet no consultaron este archivo), de la que menciona que no tuvo tiempo de consultar, pero no dice de dónde sacó dicha referencia. Es posible que haya podido ver la carátula de las copias autenticadas en donde se remite la ubicación del original en el AHT. En 1972, Zerda de Cainzo también reproduce la cédula pero no menciona su fuente ni reproduce el protocolo del testimonio, por lo cual es de suponer que su reproducción parcial la hace desde la copia "que posee Mamaní" ${ }^{47}$ ya que dice haberla comparado con la de Roman y Mullet.

Finalmente tenemos el conocido trabajo de Isla (2002) quien, a pesar de decir que "Dada la importancia del documento para el entendimiento de la historia amaicheña, como de las prácticas y discursos actuales, lo transcribo a continuación según una presentación realizada ante un ministerio público de la ciudad de Buenos Aires en 1853" (p. 52), reproduce la copia de Román y Mulet, cayendo así en el mismo error que introdujo Cano Vélez Vélez desde el principio, ya que el año de entrega del testimonio en Buenos Aires es 1753, y no 1853 como bien lo señaló quien en realidad es el primero en rescatar el texto íntegro del testimonio: Adrián Canelada ${ }^{48}$.

Pero antes de describir el rol de Canelada en esta cronología, debemos decir que en realidad la existencia de la "cédula real" entra en la bibliografía académica casi inmediatamente de producida su protocolización. Adán Quiroga y Samuel Lafone Quevedo, dada su prolongada estancia en los alrededores de Amaicha, tuvieron ocasión de interactuar con los amaicheños de entonces y plasmar tempranamente algunos comentarios respecto al conflicto por la tierra y a la existencia de la "cédula". Lafone Quevedo ${ }^{49}$ (1904, p. 124) dirá:

Estos Hamaichas han pleiteado durante un siglo con los ocupantes del Bañado de Quilmes, y hasta el día de hoy conservan la pretensión de reivindicar parte, sino el todo 
de aquella propiedad. Según los documentos, la familia de Aramburu la ocupaba con permiso de los Indios Hamaichas.

Mientras que Quiroga ${ }^{50}$ (1912, p. 156) agrega al respecto

Por un título otorgado en Buenos Aires, que posee en copia el cacique Timoteo Ayala, de mayo de 1753, ante el escribano de cabildo, hacienda y guerra, vése que los dominios del cacique Francisco Chapurfe se extendían mucho, comprendiendo los siguientes pueblos, de los que se le da posesión: Bañado de Quilmes, San Francisco, Tiopunco, Encalilla y Amaycha, de acuerdo con la cédula de abril de 1716.

Esta primera mención de la Cédula es importante en cuanto la extrae del ámbito puramente jurídico (que es en donde fue presentada y validada por el gobierno tucumano mediante su protocolización) y le otorga un carácter semipúblico. Digo semipúblico, por cuanto el público lector de las obras científicas era reducido, pero la posición política que ocupaban algunos de estos lectores jugaría en el futuro un papel decisivo en el apoyo que brindarían a la comunidad. No obstante esta primera mención de Quiroga, habrá que esperar hasta el trabajo de Canelada para conocer el texto de la cédula.

54 En 1921, en su carácter de maestro en la escuela de Calimonte, a Canelada le cupo la tarea de llevar a cabo las entrevistas para colaborar con la Encuesta Folclórica Nacional ${ }^{51}$. Motivado por un gran interés en la cultura vallista, aportó (a diferencia de sus otros colegas provinciales) más de 350 páginas con valiosa información ${ }^{52}$ sobre los más diversos temas. En una de las páginas de la encuesta bajo el título "Cédula Real" señala como "narrador" al por entonces cacique "Timoteo Ayala, de 66 años" y escribe la siguiente advertencia:

Por si pudiera ilustrar algo estos conceptos o encerrara algún interés que yo no alcanzo, como un dato curioso, tomo copia del documento llamado Cédula Real, en donde consta la concesión hecha a los ascendientes de estos habitantes de Amaycha, Calimonte y Tio Punco (Canelada 1921, p. 296).

Dado que Canelada señala a su fuente de información como "narrador" pero también usa la expresión "tomo copia" queda la duda de si en realidad el texto que escribe de la cédula es copiado desde una fuente escrita (la copia del testimonio) o dictado. Dada la diferencia en el texto que él escribe y la que publicara años después Cano Vélez, solo puedo decir que me inclino por la opción del dictado (ver luego nota 53). Ahora bien, dado que la transcripción que hiciera Canelada no ha sido publicada aún, dado que es la más antigua, y dado es que es la única que originalmente señala correctamente la fecha de entrega de 1753, aprovechamos la ocasión para transcribirla literalmente tomando como fuente el microfilm del manuscrito.

"En esta ciudad de Buenos Aires, a los seis días

del mes de Mayo de 1753, ante mi el Escri-

bano de Hacienda, Cabildo y Guerra, se pre-

sentó un indio de edad como de 75 años,

con orden de su Exmo. Sr. Gobernador y

Capitán General Don Antonio de Andomaqui,

para que le diese Testimonio de los ti-

tulos de las tierras de sus indios; dicha orden, 
la agrego a los títulos de su referencia, etcr.

-- "Nos, los Gobernadores Don Francisco de Nievar,

Gerónimo Luis de Cabrera y los Jefes del Ejér-

Cito de S.M. Real, Don Pedro Díaz Doria y

Don Francisco de Lamercado de Villacorte, reunidos en este paraje de Encalilla para dar

la posesión Real al cacique de los pueblos llama-

dos “-El Bañado de Quilmes, -San Francisco, -

Tio-Punco, Encalilla y Amaycha, Don

Francisco Chapurfe, quien nos manifestó la

Cédula Real que antes dimos en el año de $\underline{1716}$, en el mes de Abril, en la que se manifiesta que al ser bautizado su padre, el cacique de las ciudades

de Quilmes y de todos estos pueblos, Don Diego

Utibaitina, se labró y selló con nuestros

nombres un algarrobo grande y estando

reunida toda la gentilidad de Vacamaca y

Lagunas,,$^{53}$ actos en señal de la posesión de tierras

de dichos pueblos, entrepasándose estas tus

tierras quedó en nombre del rey y Nuestro

Señor amparado y ampara es entre dos

depas y que en ningún tiempo os han de qui-

tar persona alguna omeos han dado los

españoles estas tierras y antes si fueren

amparadas dichas tierras, que son desde el al-

garrobo sellado, línea recta al Naciente has-

ta dar con una loma picaza en el Puesto de

Masao y de allí por la cuchilla de Aguila

Huaci hasta dar con la cima de Los Lam

pazos, y de allí, tomando para el Sud, el

cordón que bota las aguas para el Valle has-

ta dar con el Nevado, y se vuelve para el No-

ciente por el cordón que vota las aguas para

Tafí hasta llegar a la abra que forma el cami-

no que va para este punto y de allí se mira

al cerro que está entre N.O. hasta dar con

el cordón que vota las aguas para el Tucu

mán, y volviendo por este rumbo para 
el Poniente, se toma la linea del algarrobo escrito al abra del sud del Morro de San

Francisco que mira directamente a la puerta el Chiflón del Río de Vacamaca y por el Norte hasta el Neayacocha y de allí, línea recta al Naciente a un morro alto y siguiendo la línea hasta el cordón que vota las aguas, para el Tucumán y volviendo al Neayacocha linea recta al campo del Mollar en donde plantamos una cruz grande, y de allí se tira línea recta al Poniente al Cerro Grande que está frente a Colalao, quedando este punto y Tolombón y el paraje del Sud de estos pueblos llamados “-El Puesto"- prestados por el tiempo de seis años en poder de Don Pedro Díaz Doria, para hacer pastear, y invernar tropas de mulas del Ejercito real, gracia que se hizo por haberse empeñado en cuidado con toda su pía armada a nombre de S.M. Real y el paraje de Tafí arrendado a Don Francisco de la Mercado de Villa-corte, para cabras y ovejas de Castilla, bajo cuyos límites damos la posesión Real, temporal, y corporal al susodicho cacique, para él y su indiada, sus hererederos y sucesores y ordenamos al Gran Sanchez que está a siete leguas del Tucumán abajo, deje venir a los in dios que se le recomendaron por _ _ - - ${ }^{54}$ peredo tiempo de diez años para que instruidos volviesen todos a sus casas, como dueños legítimos de aquellas tierras para que las posean ellos y sus descendientes.

Así firmamos este acta de posesión real en el referido paraje de Encalilla en dicho día, mes y año=Francisco de Nievar=Gerónimo Luis de Cabrera=Pedro Díaz Doria=Francisco de la Mercado de Villa-Corte=" Es copia 
fiel de su original, al que me refiero en caso

necesario,= En fe de ello firmo la presente

fecha ut supra=año de 1716, mes de

Abril=Martín Rodríguez=, firmado_

Escribano de Hacienda Cabildo y Guerra.-

La segunda transcripción de la cédula es de Cano Vélez, pero en realidad aparece por primera vez el 30 de marzo de 1924 en una nota de página entera de la edición dominical de La Gaceta, mas quién se encargó de que esta y otras notas aparecieran fue el abogado Carlos Heller (que años después llegaría a ser presidente de la Corte Suprema de Justicia provincial), quien a su regreso de una excursión por los valles en donde conoció a Cano Vélez, y por su amistad con el director del diario, se encargó de que las notas del maestro fueran publicadas. Sin embargo la versión publicada adolece de errores de armado de imprenta (renglones intercambiados) y como año de entrega de la cédula figura "1953" (sic).

Unos años más tarde, Mena (1930) transcribe esta versión de Cano Vélez publicada en La Gaceta, pero corrigiendo la fecha de otorgamiento por $1753^{55}$.

Tenemos en definitiva solo dos versiones de la cédula: la primera es la de Canelada de 1921, y luego la de Cano Vélez de 1924, que en definitiva fue la que sirvió de base a las publicadas posteriormente.

Lamentablemente no sabemos quién exactamente le permite a Cano Vélez obtener su versión de la cédula, pero se podría decir que la debe haber tomado a posteriori de 1921 (ya que no la menciona en los textos que remite a la encuesta folclórica ${ }^{56}$ ) pero antes de 1924, cuando se publica en La Gaceta. Dadas estas fechas, es de presumir que quien le haya permitido obtener copia fuese Timoteo Ayala y no Agapito Mamaní (con quien tenía una fluida relación según comenta Cano Vélez en su libro), quien sucedió en el cacicazgo a la muerte de Timoteo en 1938, hasta su propia muerte en $1964^{57}$. Es de suponer que más o menos hasta 1938 Timoteo haya conservado las copias, y que luego pasaran a Agapito. De haber sido Agapito quien le facilitase la copia no se entendería qué hacían en poder de él entre 1921 y 1924 y es de suponer que Cano Vélez lo hubiese nombrado en su libro cuando dice

como puede verse en una copia de la CEDULA REAL, que obra en poder de un vecino de esta y que por amistad, conseguimos nos permitiese sacar la copia que va enseguida y que a nuestro juicio tiene cierta importancia. (1943, p. 22).

Lo que queda claro de este último párrafo es que a Cano Vélez no le fue dictado el texto de la copia sino que lo transcribió de la misma. Esta transcripción es la que puede haber servido de fuente a Carrizo y a Heller para sus publicaciones. Lo que no queda claro es el porqué de la equivocación de Cano Vélez respecto al año de 1753. Si bien no he tenido la oportunidad de conocer en persona la copia, en las reproducciones de los folletos mencionados se lee claramente "mil setecientos cincuenta", por lo que no se puede adjudicar a un problema de legibilidad.

Existe una versión que dice que existían "copias" de la cédula en manos de otros vecinos de Amaicha. De ser cierta esta versión, no sería ilógico pensar que se tratase de copias manuscritas hechas desde la copia entregada por el gobierno. O podría tratarse de copias facsimilares, pero para este caso ya tendríamos que estar hablando de por lo menos la década de 1960. En este caso también podrían aparecer copias del testimonio 
pero no obtenidas en el ámbito de la comunidad, sino que estas habrían sido obtenidas del protocolo del archivo de San Miguel de Tucumán donde fue depositado en 1892. Un trabajo de encuesta entre los comuneros podría ayudar a echar luz al respecto.

En resumen, existe un testimonio (Figuras 2 y 3 ) obtenido en Buenos Aires, que data de 1753, que junto a otros papeles y una escritura de protocolización fueron depositados en el Archivo Histórico en 1892. De este conjunto, el gobierno de Tucumán por pedido de Ovando hizo una copia certificada por el escribano Sánchez, la cual fue a manos del cacique de la comunidad Timoteo Ayala. De esta copia, Quiroga (1912 [1900]) hace una mención resumida, y la primera transcripción (¿dictada?) de la copia la hace Canelada (1921). La segunda transcripción la hace Cano Vélez (1924) desde la copia. La transcripción de Cano Vélez es copiada o reproducida por Mena (1930), Carrizo (1937) y por Román y Mullet (1949). Finalmente la copia de Román y Mullet es copiada por Reyes Gajardo (1966) y por Isla (2002). Cerramos esta sección con una Tabla Resumen y un Diagrama de estas fuentes, para pasar luego a la transcripción del testimonio depositado en el AHT.

\begin{tabular}{|c|c|c|c|c|c|}
\hline \multirow{2}{*}{ Fuente bibliográfica } & \multirow{2}{*}{$\begin{array}{l}\text { Año de la } \\
\text { Fuente }\end{array}$} & \multirow{2}{*}{$\begin{array}{l}\text { Informante } \quad 0 \\
\text { Fuente }\end{array}$} & \multicolumn{2}{|c|}{ Encabezado ${ }^{58}$} & \multirow{2}{*}{$\begin{array}{l}\text { Año } \\
\text { testimonio }\end{array}$} \\
\hline & & & Sí & No & \\
\hline Quiroga & 1900 & Timoteo Ayala & -- & -- & 1753 \\
\hline Canelada & 1921 & Timoteo Ayala & $\mathrm{x}$ & & 1753 \\
\hline $\begin{array}{l}\text { La Gaceta (Cano Vélez- } \\
\text { Heller) }\end{array}$ & 1924 & "un comunero" & $x$ & & 1953 \\
\hline Mena & 1930 & La gaceta & $x$ & & 1753 \\
\hline Carrizo & 1937 & Cano Vélez & & $\mathrm{x}$ & --- \\
\hline Cano Vélez & 1943 & "un comunero" & $x$ & & 1853 \\
\hline Roman \& Mullet & 1949 & $\mathrm{~s} / \mathrm{d}$ & $\mathrm{x}$ & & 1853 \\
\hline Reyes Gajardo & 1966 & Roman-Mulet & $x$ & & 1853 \\
\hline Zerda de Cainzo & 1972 & $\mathrm{~s} / \mathrm{d}$ & & $\mathrm{x}$ & --- \\
\hline Isla & 2002 & Roman yMulet & $x$ & & 1853 \\
\hline
\end{tabular}




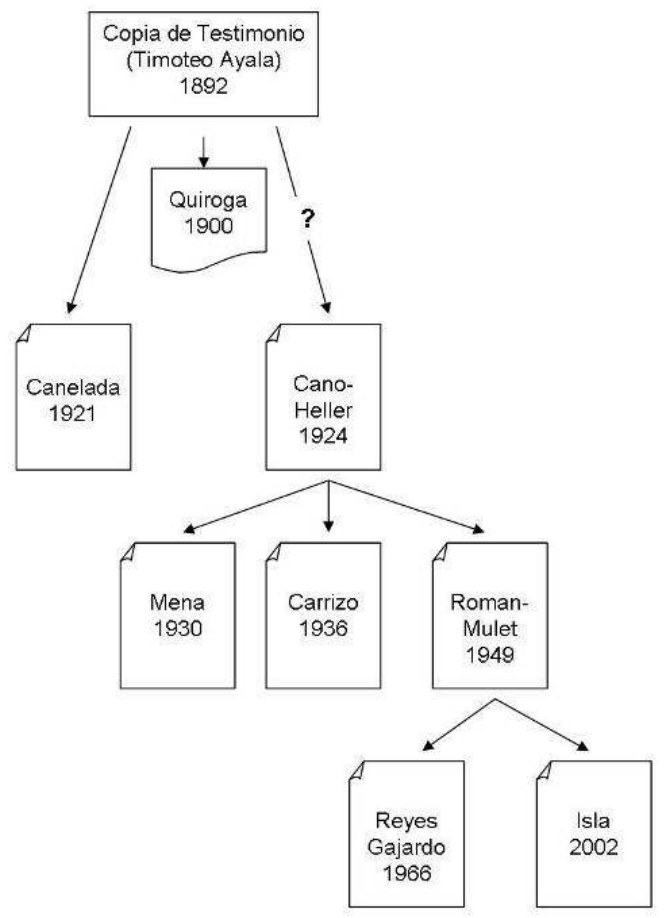

\section{Transcripción de la "Cédula Real"}

Lo que sigue es la transcripción textual del testimonio otorgado en Buenos Aires el 6 de mayo de 1753, fojas $1417(\mathrm{r} / \mathrm{v})$, protocolizado en Tucumán el 30 de noviembre de 1892, bajo escritura número 582, fojas 427 (r/v) y $428(\mathrm{r})$.

Como se indicara anteriormente, se siguen las Normas de Edición y Transcripción de los Documentos sugeridas por Corpus, publicación electrónica dependiente de la Facultad de Humanidades y Ciencias de la Educación de la Universidad de la República de Uruguay, por cuanto esta alienta las transcripciones que respetan la ortografía original y desalientan las normalizaciones modernas del texto. A posteriori se adjuntarán las imágenes fotográficas obtenidas del original, de modo tal que el lector podrá comparar el texto original con la transcripción ofrecida aquí y compararla con las versiones modernas citadas anteriormente.

Como aclaración vale la siguiente clave utilizada para señalar aspectos del texto con problemas de transcripción:

1571 Se numeran los renglones del texto original de 5 en 5 y se respeta en la transcripción la longitud original de cada línea.

$\wedge \wedge$ Señala una intercalación hecha por el autor del documento entre líneas. En nuestro caso la que se extiende entre la línea 13-14 y 14-15.

[??] Indica la presencia en el manuscrito de parte de una palabra que resulta ilegible, por

ejemplo: $\mathrm{Ba}[? ?] \mathrm{maca}$. Se colocarán tantos signos como letras ilegibles tenga la palabra

161 [**??] Indica que una palabra entera es ilegible. 
Además, a partir de la referencia numérica de renglón, se introducen unas notas aclaratorias al final de la transcripción.

Foja 1417 (r)

$=1417=$

(Crismón)

Un real

SELLO TERCERO, UN REAL

AÑO DE MIL SETECIENTOS

Y CINCUENTA Y DOS, Y CIN-

CUENTA Y TRES

1 En esta ciudad de $\mathrm{B}^{\mathrm{s}} \mathrm{A}^{\mathrm{s}}$ a los seis dias del Mes

de Mayo de mil setecientos cincuenta y

tres, ante mi el Escribano de Hacienda, Cabildo y Guer

ra, se presento un Yndio de edad cerca de setenta y cinco añ con

5 orden de S. E. el Señ. Gob ${ }^{\text {or }}$ y Cap ${ }^{\text {tan }} \mathrm{Gen}^{1}$ Don Ant ${ }^{\circ}$ de Andonaegui

para que le diese un testimonio de los titulos de las tierras de sus

Yndios: dha. orden la agrego a los títulos de su referencia [**??].

testi- ) Nos los Gobernadores Don Fran ${ }^{\text {co }}$ de Nievar y Don Geronimo

monio) Luis de Cabrera y los Gefes de S.M.R. Don Pe

10 dro Diaz Doria y Don Fran ${ }^{\text {co }}$ de Lamercado de Villacorta Re

unidos en este parage de Encalilla $\mathrm{p}^{\mathrm{a}}$ dar la posecion Real al

Cacique de [**??] P[??]blos del Bañado de Quilme San Fran ${ }^{\text {co }}$

tio Punco, Encalilla y Amaicha Don Fran ${ }^{\text {co }}$ Chapurfe, quien

$\wedge \wedge$ el año de mil setecientos

nos manifesto la Cédula Real que antes dimos:

dies $\mathrm{y}$ seis en el mes de Apriles $\mathrm{x}^{\wedge \wedge}$

en la que se manifiesta

15 que al ser Bautizado su padre el Cacique de la Ciudad de Quilmes y de todos estos Pueblos Don Diego Utibaitina se labró y Selló con Nuestros Nombres un Algarrobo grande, y estando reunida toda lä Gentilidad de $\mathrm{Ba}$ [??]maca y Lagunas, se le hizo abrazara dicho Algarrobo, coger agua en una timbe de asta; actos en señal de la posesión de tierras de dichos Pueblos; 20 entrepasandose estata tuis terras, quedó en Nombre del Rey [??]str[??] Seṛ amparado y amparaos; entre dos dipes: y que en ningun tiempo os han de quitar Persona alguna; ome os han dado los Españoles estas tierras; y antes si fuesen amparadas dchas tierras; que son: desde el algarrobo Sellado línea recta al Naciente hasta dar con una loma picasa en el Punto del Masao; y de allí por la $\mathrm{Cu}_{-}$ 25 chilla de Aguila Guaci hasta dar con la cima delos Lampazos: y de allí tomando Para el Sud el Cordon qe bota las aguas para el Valle hasta dar con el Nevado; y se bu_

elve $\mathrm{p}^{\mathrm{a}}$ el Norte $\mathrm{p}^{\mathrm{r}}$ el Cordón que bota las aguas $\mathrm{p}^{\mathrm{a}}$ tafin hasta llegar á la abra $\mathrm{q}^{\mathrm{e}}$ forma el camino $\mathrm{q}^{\mathrm{e}}$ bá $\mathrm{p}^{\mathrm{a}}$ este Punto; y de allí se mira al Cerro que está entre N.E. hasta dar con el Cordón $\mathrm{q}^{\mathrm{e}}$ bota las aguas para el tucuman: y bolviendo pa_ Foja 1417 (v)

30 este rumbo para el Poniente; se toma la línea del Algarrobo escrito á la abra del Sud del Morro de San Fran ${ }^{\mathrm{co}} \mathrm{q}^{\mathrm{e}}$. mira directamente a la Puerta del Chiflón del Rio de B[???????]ca: y pr el Norte hasta el Neayacocach. y de alli línea recta al Naciente á un morro alto, y siguiendo la línea hasta el cordon $\mathrm{q}^{\mathrm{e}}$ bota [????]uas para el tucuman, y volviendo al Neayacocach [**??][**??] 35 al Cam[????]l Moyár en donde plantamos una Cruz Grande, y de allí se tira linea [???]ta al Poniente al Cerro Grande qe está frente á Colalao: que dando este P[??] to y tolombón, y el Paraje del Sud de estos Pueblos, llamado el Puesto, prestados por el tiempo de seis añ. en poder de D ${ }^{\text {on }}$ Pedro Díaz Doria, 
para se pastear y inbernar tropa de mulas del Egercito Real; gracia que se 40 hizo, por haberse empeñado en Cuidado qon toda su pía Armada á N. de S. M. R. y el paraje de tafín arrendado a Don Fran ${ }^{\text {co }}$ de Lamercado de Villacorte, para se pacer Cabras y Ovejas de Castilla: Bajo cuyos límites damos la posesión Real, Temporal y Corporal al susodho Caci_ que, para él, su Indiada, sus herederos y sucesores: Y ordenamos al Gran 45 Sánchez que está siete leguas de Tucumán abajo, dege benir á los Indios que se le encomendaron por el referido tiempo de diez años para que ynstruidos [**??][**??][*??] como dueños legítimos de aquellas tierras [**??] las posean ellos y sus descendientes: $Y$ así firmamos este acto de Posesión Real en el referido Parage de Encalilla, en dho día, mes y 50 año=Francisco de Ni[????]=Gerónimo Luis de Cabrera=Pedro Díaz Doria=Fra ${ }^{\mathrm{co}}$ de Lamercado de Villacorte=Es copia fiel de su horiginal al que me refiero en caso necesario; en fee de ello, firmo la presente, fha ut supra=Entre líneas=año de 1716 y mes de Apriles vale. 55 D[???][**??] (Signo de Martín Rodriguez la Cruz y Firma). E. de $\mathrm{H}^{\text {da }} \mathrm{C} .{ }^{\text {do }}$ y Guerra.

\section{Observaciones:}


Figura 1. Fotografía del protocolo 86 , Tomo Tercero, Serie C, de 1892, donde se encuentra el Testimonio

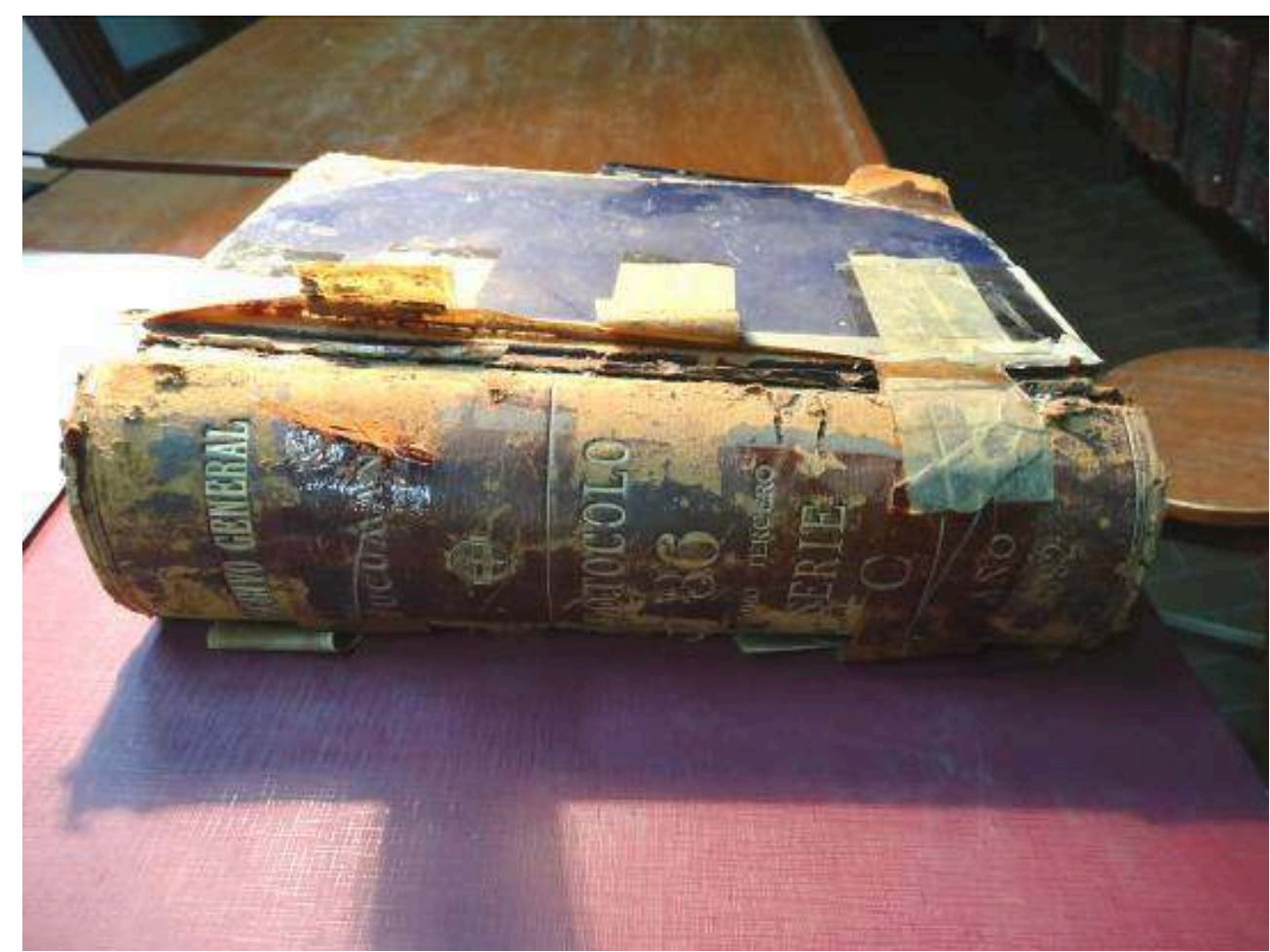

Figura 2. Foja 1417 (r)

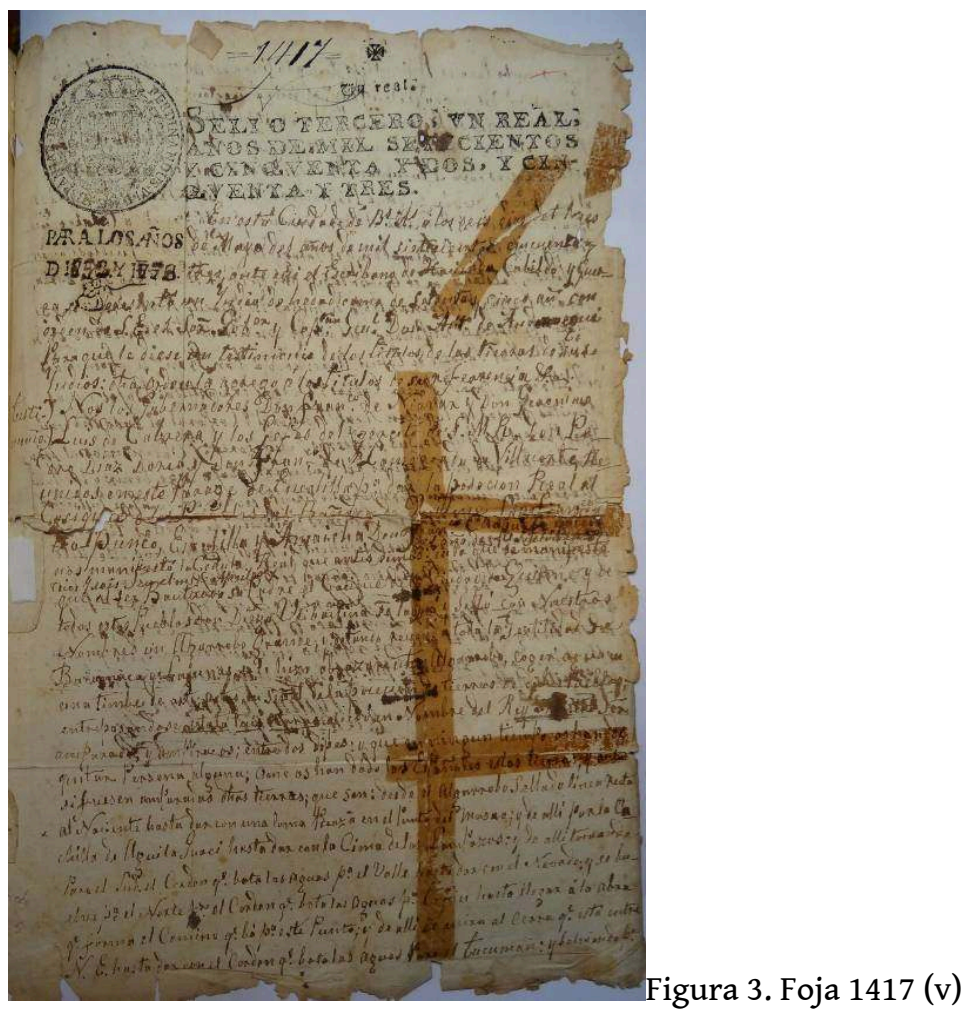




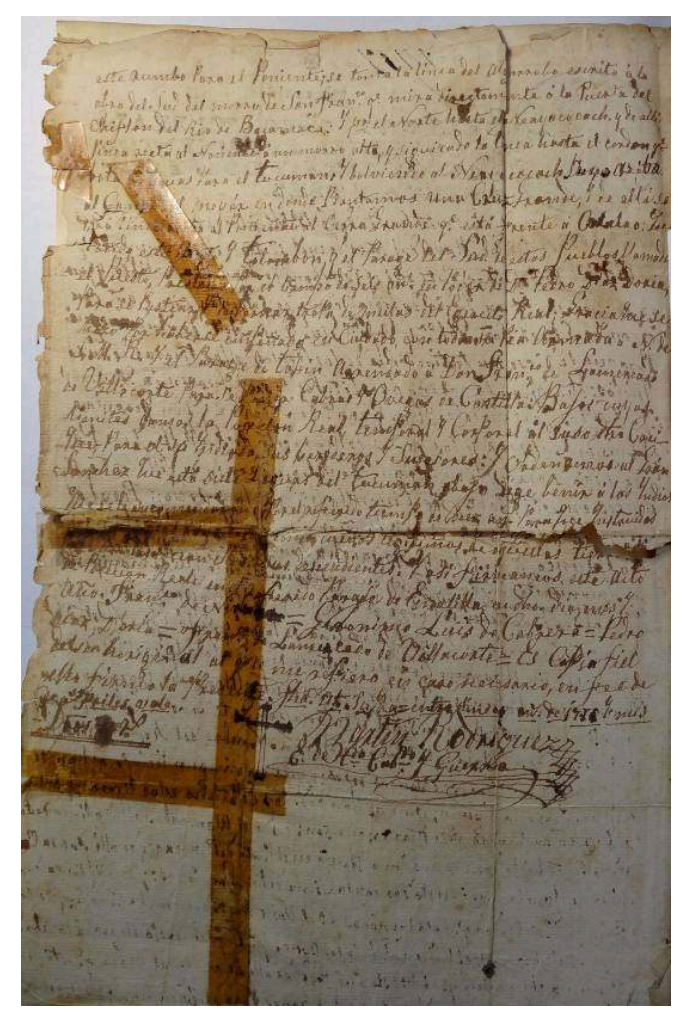

\section{Reflexiones}

Para finalizar me gustaría compartir un par de reflexiones metodológicas fruto del trabajo en archivos, que creo puede ser útil no a especialistas sino a quienes se están acercando al tratamiento documental. Insisto, tratar con documentos antiguos puede ser arduo pero es un trabajo insoslayable si ese documento es una pieza importante en nuestra investigación. Si bien esto parece una perogrullada, algunos de los ejemplos aquí expresados muestran que no está de más recordarlo. Desde luego, no se trata de rechazar las numerosas transcripciones ya efectuadas, las mismas pueden constituir nuestro punto de partida y ser una guía fundamental, pero si el original está a un alcance más o menos inmediato, merece el esfuerzo de echarle una mirada. Paralelamente el tiempo en que nos toca investigar juega a nuestro favor a través de las numerosas digitalizaciones que se encuentran disponibles a través de Internet, como por ejemplo la del Portal de Archivos Españoles (PARES, www.pares.mcu.es) que nos permite visualizar y recibir en nuestro email copias de los archivos. Este último caso es ejemplo y contraejemplo interesante, ya que la facilitación de la búsqueda a través del buscador se ve contrarrestada por la confiabilidad de la base de datos asociada. Por ejemplo si se trata de buscar información sobre los indios famayllaos (cuya encomienda da lugar al actual pueblo de Famaillá al sur de Tucumán), no se encuentra nada debido a que quien hizo la indización del documento parece haber leído "jamayllap" cuando en el documento se lee claramente "famayllao" ${ }^{59}$. En los índices del AHT, insoslayables como punto de partida, también suelen también filtrarse errores de este tipo aunque menores. Seguramente que cada uno podrá aportar sus sorpresas y desencuentros; lo que me interesa reforzar aquí es una cuestión metodológica básica de la investigación: la etapa de exploración de fuentes debe seguir siendo tan rigurosa como el resto de la investigación. Las citas de citas tienen riesgos ya conocidos, por lo cual caer en ellos ya 
no puede ser considerado un simple error. Algo similar suele ocurrir con las citas bibliográficas.

Estas observaciones apuntan a retomar o enfatizar lo que ya hace tiempo advertía Romano (1992) sobre la necesidad de ponderación de las fuentes y sus "defectos" antes de decidir sobre qué metodología de análisis utilizar. Al reflexionar sobre el aspecto cualitativo de las fuentes consideradas en sí mismas, insistir en la necesidad de preguntarse “¿cuál es su valor?, ¿qué confianza es posible tener en ellas?" (Romano 1981, p. 204). Y refrescar esa ya vieja advertencia sobre la necesaria mirada crítica de las fuentes de investigación, ya que sin ella se pierde también el contexto y con ello una cabal interpretación de las mismas.

En el caso particular del documento que aquí se trató, la existencia bibliográfica de distintas "versiones" (aunque con variaciones técnicamente leves) fue motivo suficiente para iniciar una búsqueda sistemática de las mismas, compararlas y tratar de hacer una cronología regresiva de ellas, con lo cual quedó claro que las versiones no eran tales sino simples copias de copias, aunque en algunos casos no fueran declaradas como tales ${ }^{60} \mathrm{y}$ además fueran introduciendo pequeños cambios ${ }^{61}$. La inconsistencia más obvia y relevante (1753 vs. 1853) fue motivo suficiente para tratar de encontrar el "original" de la "cédula" y gracias a esto se encontró lo que en su momento podría ser considerado la "versión" más antigua (el testimonio), que además quedaba perfectamente contextualizado en una coyuntura que fue crucial para los amaichas históricos en su centenaria pelea por la tierra.

179 Para el caso que nos ocupa, trabajar con la fuente original permitió ver la diferencia entre 1753 y 1853 y evitar errores de interpretación ${ }^{62}$. Por ejemplo, respecto a los actores involucrados, situar el documento en 1853 podía inducir a pensar que el mismo podría haber sido solicitado por Lorenzo Olivares, mas, dado que la fecha correcta es 1753, no podría haber sido, ya que en el censo de $1791^{63}$ Don Lorenzo aparece teniendo 50 años. Esta sencilla modificación nos obliga a preguntarnos entonces ¿quién fue el "Yndio de edad cerca de 75 años" que menciona el escribano porteño?, ¿mediante qué procedimientos logró el apoyo del gobernador Andonaegui? y ¿por qué motivos en fecha tan temprana debe hacer este pedimento?; ¿es posible que los terrenos "prestados" por 6 años a "Pedro Díaz de Doria" en "1716" se hubiesen convertido en una de las causas?

180 Rodríguez y Boullosa (2013) han señalado ya la importancia de las autoridades viajeras de Amaicha en el devenir de sus históricas luchas por la tierra, trazando una línea que va desde mediados del siglo XVIII, con Olivares, hasta el actual cacique Nieva (a la cual deberíamos sumar la anónima figura de 1753), en donde se destaca la necesaria diferenciación de estos líderes respecto a sus representados, en tanto su capacidad de interactuar con el sistema judicial de su época. El hecho de tener documentos manuscritos por los propios litigantes es en sí mismo una fuente de información complementaria. El tipo de letra usada, la caligrafía, el estilo de redacción, el uso del espacio en la foja, el tipo de firma, etc., son elementos de información complementarios sobre ciertos aspectos del redactor que no siempre son explícitos. El hecho de que un representante sepa escribir una nota no es lo mismo que el hecho de que la haya escrito con una buena caligrafía, que haya respetado los formatos de márgenes establecidos por convención para los oficios y que para finalizar haya usado una firma adornada. Quien haga esto último es una persona que por algún motivo ha recibido una preparación distinta a la del simple escolar. 

expuesto que ha servido hasta el presente para plantear cuestiones territoriales en diferentes ámbitos y por distintos actores. Quizás por influencia de la lectura de Carrizo (1937), o proyectando consciente o inconscientemente un preconcepto sobre una territorialidad basada en áreas de explotación, más de un autor (entre los que me incluyo) ha llegado a sostener que el territorio devuelto a los amaichas mediante la cédula seguramente correspondía de alguna manera (aunque ampliado) con el territorio prehispánico de estos. Sin embargo creo que estamos muy lejos de poder afirmar esto. En ninguna parte del texto aquí transcripto dice algo al respecto, las investigaciones arqueológicas están muy lejos (en términos teóricos y metodológicos) de poder mostrar alguna correlación en ese sentido, y la investigación de fuentes etnohistóricas e históricas muestran que si bien seguimos avanzando, cuanto más sabemos de los amaichas más preguntas quedan aún sin respuestas.

\section{BIBLIOGRAPHY}

Avellaneda, N. (1865). Estudio sobre la leyes de Tierras Públicas. Buenos Aires: Imprenta del Siglo.

Avellaneda, N. (1910). Escritos y Discursos de Nicolás Avellaneda. Tomo VI. Buenos Aires: Compañía Sudamericana de Billetes de Banco.

Bazán, A. (1987). Economía y comercio del noroeste antes del ferrocarril: 1860-1890. Buenos Aires: Academia Nacional de la Historia.

Bruno, C. (1976). Historia de la Iglesia en la Argentina. Vol. XI. Buenos Aires: Editorial Don Bosco.

Campi, D. (2002). La conformación del mercado de trabajo en Tucumán (1800-1870). Trabajo y sociedad, 5(IV). Santiago del Estero. Disponible en http://www.unse.edu.ar/trabajoysociedad/ CAMPI.htm

Canal Feijóo, S. (1951-IX-23). Viaje al fondo de las proximidades. La "Comunidad" de Amaicha del Valle. Diario La Nación, p. 3. Buenos Aires.

Canelada, A. (1921). Valle Calchaquí. Calimonte. En Encuesta Folclórica Nacional. Microfilm disponible en INAPL. Manuscrito.

Cano Vélez, F. (1943). Amaicha del Valle. Buenos Aires: ETA.

Cano Vélez, M. (1949). Escuela Nacional № 10 “Claudia Vélez de Cano” Tucumán. Su Historia

(Período 1895 - 1949). Manuscrito.

Carlin, R. (2003). A paleographic guide to Spanish abbreviations 1500 - 1700. Boca Raton: Universal Publishers. 
Carmignani, L. (2013, diciembre). Las visitas de los tenientes de naturales a los partidos de pueblos de indios de la gobernación del Tucumán. (1606-1607). Corpus [En línea], 3 (2) Disponible en http://corpusarchivos.revues.org/548

Carrizo, J. (1937). Cancionero Popular de Tucumán. Tucumán: Universidad Nacional de Tucumán. Chamosa, O. (2012). Breve historia del folclore argentino (1920-1970). Buenos Aires: Editorial Edhasa. Conti, V. y Sica, G. (2011, enero). Arrieros andinos de la colonia a la independencia. El negocio de la arriería en Jujuy, Noroeste Argentino. Nuevo Mundo Mundos Nuevos [En línea]. Disponible en http://nuevomundo.revues.org/60560

Díaz Rementería, C. (1988). Comunidades y tierras comunes en las provincias argentinas de Tucuman y Jujuy. Actas del Congreso Internacional de Historia de América, Tomo I, 429-442.

Espeche, F. (1875). La provincia de Catamarca. Buenos Aires: Imprenta Biedma.

Floriano Cumbreño, A. (1946). Curso general de paleografía y paleografía y diplomática españolas. Oviedo: La Cruz. Universidad de Oviedo.

García Larragueta, S. (1979). Prenotanda sobre normas de transcripción. En Documentación y archivos de la colonización española (Tomo I, pp. 191-194). Madrid: Ministerio de Cultura. España.

Garcés, J. (1961). Cómo han de traducirse los documentos paleográficos de Hispanoamérica. Quito: Publicaciones del Museo Municipal de Arte e Historia, Vol. 31.

Gentile, M. (2012). Geografía y política. La gobernación de Tucumán en 1582, según la Relación de Pedro Sotelo Narváez. Anuario Jurídico y Económico Escurialense, XLV, 581-608. Disponible en http://www.rcumariacristina.net:8080/ojs/index.php/AJEE/article/view/125/113

Herrera, C. (2009). Los Avellaneda: herencia y poder en la élite tucumana. Segundas Jornadas Nacionales de Historia Social. La Falda, Córdoba. Argentina

Isla, A. (2002). Los usos políticos de la memoria y la identidad. Indigenismo y Estado. Buenos Aires: De las Ciencias.

Justiniano, M. y Tejerina, M. (2005). Estado, finanzas y familias: los presupuestos provinciales y su ejecución. El caso de la provincia de Salta (1880-1914). Andes, 16, 275-302.

Lafone Quevedo, S. (1904). Viaje a los menhires e intihuatana de Tafí y Santa María en octubre de 1898. Revista del Museo de La Plata, XI, 123-128.

López Villalba, J. (1998). Normas españolas para la transcripción y edición de colecciones diplomáticas. Espacio, Tiempo y Forma (Serie III, Ha Medieval), 11, 285-306). Madrid: UNED.

Meister, A., Petruzzi, S. y Sonzogni, E. (1963). Tradicionalismo y cambio social. Rosario: Facultad de Filosofía y Letras, Universidad Nacional del Litoral.

Mena, F. (1930). Jurisdicción del Valle de Calchaquí. Salta: Escuela Tipográfica Salesiana.

Mendoza Cuevas, A., Correa, M. y Quezada, A. (2009). Identificación de tintas metalogálicas en manuscritos históricos mediante análisis no destructivo combinado de espectrometría fluorescencia de rayos x y ultravioleta-visible. Revista Cubana de Química, XXI (1), 38-45.

Odor Chávez, A. (2009). Tintas Ferrogálicas: su composición y principales mecanismos de transformación. Hipertexto: www.adabi.org.mx/content/Notas.jsfx?id=384

Paz, G. (2006). Reseña del libro de Isla, Alejandro. 2002. Los usos políticos de la identidad. Indigenismo y Estado. Memoria Americana, 14, 219-221. http://www.seccionetnohistoria.com.ar/ memoam/Memoria_Americana_14.pdf 
Quiroga, A. (1992 [1929]). Folklore Calchaquí. Buenos Aires: TEA.

P.R.I.A. (1974). Primera Reunión Interamericana sobre Archivos. En Boletín Interamericano de Archivos, I, 83-102.

Real Díaz, J. (1970). Estudio diplomático del documento indiano. Sevilla: Escuela de Estudios Hispano Americanos.

Reyes Gajardo, C. (1966). Motivos culturales del Valle de Tafíy de Amaicha. Tucumán: Fondo Nacional de las Artes y Consejo Provincial de Difusión Cultural.

Román, M. y Mulet, F. (1949). Planificación integral del Valle de Amaicha. Tucumán: Universidad Nacional de Tucumán, Instituto de Sociografía y Planeación.

Romano, R. (1981). La historia, hoy. Revista Internacional de Ciencias Sociales, XXXIII (4), 701-710. UNESCO. Disponible en: http://unesdoc.unesco.org/images/0004/000476/047608so.pdf

Romano, R. (1992). De nuevo acerca del movimiento de precios en Buenos Aires en el siglo XVIII. Boletín del Instituto de Historia Argentina y Americana 'Dr. E. Ravignani' (Tercera serie), 6, 149-172.

Romero Andonegi, A. (2006). Criterios metodológicos adoptados para la transcripción de toponomástica tardo-medieval en el proyecto de indexación del AHEB-BEHA. Fontes linguae vasconum: Studia et documenta, 38 (12), 353-368. Navarra: Institución Príncipe de Viana. Disponible en: http://dialnet.unirioja.es/descarga/articulo/2040532.pdf

Rodríguez, L. (2009). Los usos del sistema judicial, la retórica y la violencia en torno a un reclamo sobre tierras comunales. Amaicha del Valle, siglo XIX. RUNA, XXX (2), 135-150.

www.scielo.org.ar/pdf/runa/v30n2/v30n2a03.pdf

Rodríguez, L. y Boullosa, M. (2013). “Siempre hemos buscado gente que asegure la tierra”. Viajes, autoridades étnicas y trayectorias de poder en Amaicha del Valle. Ponencia en X Reunión de Antropología del Mercosur. Córdoba, Argentina. Una versión en inglés se puede consultar en http:// nuevomundo.revues.org/66124 ; DOI : 10.4000/nuevomundo.66124

Rodríguez Espada, J. (1984). Historia de la Comunidad de Amaicha del Valle. IV Jornadas Culturales del Valle Calchaquí, 45-52. Tucumán: Universidad Nacional de Tucumán.

Santamarina, E. (1945). Notas de antropogeografía del valle de Tafí. Tucumán. Instituto de Estudios Geográficos. Universidad Nacional de Tucumán.

Silva Prada, N. (2001). Manual de paleografía y diplomática hispanoamericana. Siglos XVI, XVII y XVIII. Universidad Autónoma Metropolitana. México.

Soria, M. (1908). Geografía de la Provincia de Catamarca. Catamarca: Ed. Talleres Tipográficos de La Ley.

Sosa, J. y Lenton, D. (2009). Oralidad, territorialidad y etnogénesis de un pueblo originario: la Cédula Real de Amaycha del Valle. En Manasse, B. y Arenas, P. (Comp.), Arqueología, tierras y territorios: conflictos e intereses. Santiago del Estero: Editorial Lucrecia.

Tanodi, B. (1992). Grafística precolombina e hispanoamericana. Córdoba: Centro Interamericano de Desarrollo de Archivos.

Tanodi, B. (2001). Glosario de términos del siglo XVII. Anuario de la Escuela de Historia, 1 (1), 239-246.

Yangilevich, M. y Míguez, E. (2010). Justicia criminal y Estado en la frontera de Buenos Aires, 1852-1880. Boletín del Instituto de Historia Argentina y Americana 'Dr. Emilio Ravignani', 32, 107-137. 
Zavalía, M. (2003). Decretos del Gobierno de Alejandro Heredia (1832-1838). Colección Documentos Argentinos, Serie IV, Vol. 6. Archivo Histórico de la Provincia de Tucumán.

Zerda de Cainzo, H. (1972). Cuaderno de Humanidades, 1 (1), 29-57.

\section{NOTES}

1. Tomado de la presentación del representante de los amaichas (ver referencia en Presentación de la Fuente).

2. Titulada "Amaycha, la identidad persistente. Procesos de Territorialización, Desterritorialización y Reterritorialización de una Comunidad Tricentenaria (S. XVII-XX)”. Facultad de Filosofía y Letras, UBA.

3. Si bien en el 2007 elaboré un trabajo de georreferenciación para la comunidad de Amaicha, estando en ese momento como cacique el Prof. Mario Quinteros, desde entonces la posibilidad de ahondar en diversas fuentes plantea la necesidad de rever dicho trabajo. Vale esta aclaración a sabiendas de que a finales del 2013 finalizó el trabajo de Relevamiento Territorial encarado por el INAI (en el marco de la ley de Emergencia Territorial 26.160) en la zona de Amaicha, el cual tomó como guía dicho trabajo de georreferenciación.

4. Dicha desconfianza no es arbitraria por cuanto quienes han trabajado en archivos históricos son testigos de numerosos errores en que incurren las transcripciones, incluso cuando solo se trate de hacer índices. Al respecto se pueden ver los trabajos de Gentile (2012) o Carmignani (2013).

5. La Dra. Lorena Rodríguez me facilitó en junio del 2012 unas fotos de este material que tuvo la posibilidad de registrar el 3 octubre de 2011, cuando el tomo en cuestión todavía se hallaba en el Archivo General de Tucumán. Este material sin embargo tenía poca definición, lo cual, sumado a la curiosidad que despertaba el documento, me motivó a querer verlo in situ.

6. El "Ingeniero", como se lo conoce en el Archivo Histórico de Tucumán al Sr. Juan Carlos Medina, es un generoso auxiliar e informante de cuanta persona se acerque al archivo en búsqueda de cualquier información. Parece que todo el material que allí se deposita ha pasado por sus manos y su lúcida memoria sirve de guía en las búsquedas.

7. Una muestra previa del mismo puede ser consultada en Sosa y Lenton (2009).

8. Al momento de presentación final de este artículo (febrero 2015) la tesis ya se halla concluida y presentada en la Facultad de Filosofía y Letras, UBA: “Amaycha, la identidad persistente. Procesos de Territorialización, Desterritorialización y Reterritorialización de una Comunidad Tricentenaria (S. XVII-XX)"

9. Al respecto Díaz Rementería (1988, pp.439-440) dice que se trata de un "traslado de la toma de posesión".

10. La pérdida de documentos históricos antiguos (p.e. el diccionario kakano de Bárzana) y modernos (las Actas de 1853), es una constante ya bastante conocida por todos, por lo cual no hace falta recurrir a un largo listado de ejemplos.

11. Ver más adelante los comentarios de Carrizo.

12. Dichos mecanismos de ocultamiento no serían exagerados si recordamos los actos de violencia ocurridos durante el siglo XIX en contra de los comuneros (ver Rodríguez 2009, pp. 143-4), y aún en fechas más tempranas, como por ejemplo en la virulenta década de 1970 contra el cacique Silva quien fue detenido y golpeado. El comunero Eduardo Flores me contaba esto en 2012, diciendo "lo han botao allá en los Poroguillos para quitarle la cédula".

13. De aquí en adelante AHT. El mismo se encuentra en la calle 25 de mayo 487, de la ciudad de San Miguel de Tucumán; puede ser consultado parcialmente a través de http:// www.tucuman.gov.ar/archivohistorico 
14. De aquí en adelante SP.

15. Sobre este ítem se contó con la valiosa colaboración y material de lectura suministrados por la especialista en conservación y restauración Nora Altrudi.

16. Las mismas pueden ser consultadas en www.historiadelaslenguasenuruguay.edu.uy/corpus/ pdf/normasdeedicionytranscripcion.pdf

17. Sigifredo Brachieri, natural de Catamarca, era el esposo y representante de la viuda de José Aramburu.

18. AHT, SA, Vol. 117, f. 523 (r/v).

19. Balentin Armella ocupó el cargo de comandante militar desde 1868, ocupando también eventualmente desde 1880 hasta 1882 el cargo de comisario de Encalilla y Amaicha. Es necesario indicar que hasta principios del siglo XX, administrativamente, lo que hoy es el departamento de Tafí del Valle se componía de dos distritos: Tafí de Valle (actual municipio de Tafí del Valle) y Encalilla (actuales comunas de Amaicha y Colalao). Encalilla a su vez era departamento militar. Y por último Encalilla era el nombre de la población (que daba nombre a las jurisdicciones) que se ubicaba en las proximidades de la confluencia del río de Amaicha y el de Santa María, y en el censo de 1869 arrojaba una población de 1439 habitantes.

20. Hermano menor de Nicolás Avellaneda y el único residente en Tucumán de los cuatro hermanos.

21. AHT, SJ, 1850, Caja 6, Exp. 4.

22. Desde el 1ำ de mayo lo era transitoriamente por renuncia de Vélez Sarsfield. AHT, SA, 1872, Vol. 117, f. 250 (v/r).

23. El texto dice "Digase al solicitante que el PE no puede asumir injerencia en un asunto que pertenece a la Administración interna de una Provincia; pero que tomando en consideración la situación precaria en que vendrían a quedar las personas que representa el solicitante, su número, las dificultades y los conflictos que trae consigo el desalojo de una población numerosa que no tiene donde asiliarse, se dirige con esta foja al Gobierno de Tucumán recomendando a su equidad este asunto a fin de que haga lo que sea legalmente posible a su favor." AHT, SA, 1872, Vol. 119, fs. 131 y 132 (v/r).

24. Esta carta es fácilmente localizable en el AHT, y su estado de conservación es muy bueno. Transcribo la parte principal del texto omitiendo solo la introducción y cierre de rigor.

25. AHT, SA, 1872, Vol. 119, f. 156 (v/r).

26. Esta observación no ignora que en la documentación de la época nunca se menciona el término territorio, sino terrenos, campos o extensiones.

27. La calificación de laboriosos los aleja de la imagen del bárbaro, lo cual es muy bien visto por el autor de Estudio sobre las Leyes de Tierras Públicas (Avellaneda 1865), quien al igual que Sarmiento tenía puestos los ojos en el modelo de los "farmers" estadounidenses.

28. En su discurso al Congreso Nacional del 14 de agosto de 1878, en apoyo a la etapa final de ocupación de la Patagonia, Avellaneda sostendría: “Hasta nuestro propio decoro, como pueblo viril, nos obliga a someter cuanto antes, por la razón o por la fuerza, a un puñado de salvajes que destruyen nuestra principal riqueza y nos impiden ocupar definitivamente, en nombre de la ley del progreso y de nuestra propia seguridad, los territorios más ricos y fértiles de la República”. (Avellaneda 1910, p.234).

29. Tal vez una mirada al Archivo Privado Helguera, al que hace referencia Herrera (2009), pudiera dar con alguna pista al respecto.

30. Esta noticia así fechada aparece en un documento posterior del 20 de octubre de 1881: AHT, SA, 1881, Vol. 150, fs. 92 (r/v) y 93 (r).

31. AHT, SA, 1881, Vol. 150, f. 39 (r/).

32. AHT, 1845, SJ, Serie A, Caja 82, Exp. 31, f. 79 (v). 
33. Al respecto pueden verse los trabajos de Campi (2002), Justiniano y Tejerina (2005), Yangilevich y Míguez (2010), entre otros.

34. Lafone Quevedo (1904, p.124) describe que en 1898 hace una excursión a los menhires de Tafí y que en su camino pasaron por la "casa del rengo Timoteo Ayala, hombre bueno, que había sido mandón del lugar bajo las órdenes de don Miguel Estevez de Tafí, pero había sido removido a causa de no se qué quejas de algunos vecinos. El hombre perdió el uso de una pierna por una desgracia con el propio fusil". Contrástese esta categorización de "mandón" con la que hace Quiroga (1912) de "cacique".

35. AHT, ADM, 1881 (6 de octubre), Vol. 150, fs. 39-40 (v/r).

36. AHT, ADM, 1884, Vol. 161, f. 250 (v/r).

37. Este cruce de acusaciones hacia y entre los representantes de turno de la comunidad, se repetirán a lo largo del tiempo (Canal Feijoo 1951) hasta la actualidad (Isla 2002),

38. Véase el fragmento de entrevista que reproducen Rodríguez y Boullosa (2013).

39. De quien Cano Vélez Vélez (1943) informa es español.

40. "La industria de alfalfares para invernar ganados destinados á la exportación, está casi perdida. La industria minera floreciente en épocas ya lejanas, no existe hoy...” (Soria 1908, p.52).

41. Si bien es una hipótesis a confirmar y que aún merece un análisis fino y entrecruzado con otros datos demográficos (por ejemplo actas de defunción), es posible que esta diferencia de habitantes pueda estar explicada por las dos epidemias que sucedieron entre los dos censos, y por el hecho de que el segundo censo haya sido hecho en el mes en donde la zafra ya estaba en funcionamiento.

42. En la que estamos actualmente trabajando en el marco de la tesis en curso.

43. Así reseñaba Espeche (1875, p. 340) esta controversia de límites y vecinos "Santa María es mui visitado por tucumanos, ya por hacer negocio, ya por mudar de temperamento. Estos ingratos enfermos no pierden tiempo en persuadir a los santamarianos de que deben separarse de Catamarca i unirse a Tucumán".

44. Contrariamente a lo que podría pensarse, esta cuestión del límite entre Santa María y Amaicha no es cosa del pasado. Aún se encuentra en suspenso y se ha visto reflejada en la reciente presentación del 23 de junio de 2014, del Atlas Tucumán 100k encargado al IGN (http:// ign.gob.ar/node/786). En esta obra, hecha con la última tecnología de georreferenciación, la omisión del hito del Masao (lo cual es acorde al Anexo 2 de la ley 22.449, que, dicho sea de paso, tiene errores de topónimos) ha generado que quede fuera de la jurisdicción de la provincia de Tucumán un poblado llamado Los Colorados, perteneciente a la Comunidad de Amaicha, lo cual ya es tema de litigio.

45. AHT, SA, 1881, Vol. 150, f. 92 (r).

46. En el texto de Carrizo no se especifica si Cano Vélez se la dicta de memoria o si recurre a un escrito.

47. No queda claro tampoco si se refiere a Agapito Mamaní que había muerto en 1964 (si bien el trabajo es publicado en 1972 su redacción podría ser anterior a 1964) o a su hijo José Mamaní (ya fallecido).

48. Si bien existen algunas otras versiones publicadas (como por ejemplo la de Zerda de Cainzo 1972) hemos tomado solo estas por ser las más difundidas o las que han sido tomadas como fuentes por otros investigadores.

49. Si bien el año de publicación es de 1904, un pie de título acota que el viaje fue hecho en 1898 .

50. Si bien es publicado en 1912, el trabajo está fechado por el autor el 10 de julio de 1900. Este pequeño artículo de Quiroga es sumamente rico en información sobre la evolución del poblamiento en la zona, por lo que no puede dejar de ser leído por quien desee conocer la visión de un contemporáneo del proceso de transformación de la Amaicha de los siglos XIX-XX.

51. Sobre detalles y antecedentes histórico-contextuales de la Encuesta Folclórica puede consultarse el trabajo de Chamosa (2012), páginas 50 y siguientes. 
52. La misma fue consultada en la biblioteca del Instituto Nacional de Antropología y Pensamiento Latinoamericano de la Ciudad de Buenos Aires, en donde se encuentra en formato de microfilm.

53. En esta línea se produce la mayor diferencia respecto a la versión de Cano Vélez y al original ya que entre la palabra "Lagunas" y "actos..." falta la expresión "se le hizo abrazara dicho Algarrobo, coger agua en una timbe de asta". Dicha ausencia, es la que me inclina a pensar que la misma le fuese dictada.

54. Las primeras cuatro letras no se entienden. En la versión original la palabra es "referido".

55. Tal vez su formación en historia le permitiera haber notado que los títulos que ostentaba el escribano como gobernador Andonaegui no pertenecían a 1853 sino a 1753.

56. Cano Vélez y su hermano Miguel, ambos maestros en Amaicha, también se encargaron de recoger información para la Encuesta que volcaron en dos carpetas totalizando 63 páginas, pero no hacen mención al régimen de tenencia de la tierra ni a la cédula. Miguel, menos famoso que su hermano Félix Ramón, le sucedió a este en la dirección de la escuela № 10 de Amaicha y ha dejado muy interesantes datos en un manuscrito (Cono Vélez, M. 1949), aunque no menciona nada sobre la cédula. Este ms. me fue facilitado por el excacique de la comunidad Prof. Mario Quinteros.

57. Las fechas de muerte de los caciques son tomadas de Zerda de Cainzo (1972), sin embargo es necesario chequearlas ya que otra fuente, Giménez Espada (1984, p.50), señala como año de la muerte de Timoteo el año 1934.

58. Por "Encabezado" se entiende el texto que antecede al Testimonio en donde se menciona la fecha de creación del mismo, 1753. Aquellos que se basaron en el trabajo de Cano Vélez, pero que en sus reproducciones no incluyeron el encabezado, no reprodujeron el error de fechar el testimonio en 1853.

59. En este documento, hasta la descripción resultaba engañosa por cuanto describía al documento como "Confirmación de Encomienda de Jamayllap y Calchaquies" dando a entender dos sujetos, cuando en realidad el sujeto de la encomienda en el documento se describe como "... Pueblo de famayllao calchaquíes..." Intercambios via mail con el Archivo de Indias (mientras se escribía este artículo) permitieron informar de estas diferencias para su corrección, por lo que desde septiembre de 2014 es fácilmente ubicable por “famaillao" (http://pares.mcu.es/ ParesBusquedas/servlets/Control_servlet)

60. Por ejemplo, el trabajo de Román y Mullet no menciona su fuente.

61. Por ejemplo, algunas versiones convierten los números expresados en letras en cifras.

62. Un ejemplo de esto es la reseña de Paz (2006, p. 219) quien en base a la fecha de 1853 (tomada de Isla 2002) llegó a plantear que "La tradición comunal sostiene que la Cédula fue oficializada por el cabildo de Buenos Aires en 1853... La elección de 1853 como fecha fundante en la ficcionalización histórica comunitaria no parece ingenua. Ese fue el año de la unificación nacional por medio de la Constitución y es probable que los amaicheños desearan imbricar su propia historia con el devenir nacional".

63. Depositado en el Archivo General de la Nación, Sala XIII, 17-2-1, Leg. 2, Libro 6, fs. 37-38.

\section{ABSTRACTS}

The document presented here is the testimonio given to the Amaicha Indians in Buenos Aires in 1753. This document is deposited in the Historical Archive of Tucumán, and its condition of preservation is very poor. This testimony has served as evidence in the proceedings held between 
commoners and a landowner from Salta. Since this is an important document that has supported the Amaicha Indians' territorial claims, it has been reproduced and analyzed by different authors, though not from the original version but from a twentieth century literary source, producing a series of "copies of copies" thus perpetuating errors. In this work we transcribe the testimony inserted in the file of the registration. The main objective is to provide the original text of the document and to reduce the number of misinterpretations. On the other hand we systematize the modern versions and note some or their inconsistencies. Finally, we make some reflections about the spatial, political and socio-historical implications around the testimony.

El documento que aquí se presenta es un testimonio entregado a los indios de Amaicha del Valle, fechado en Buenos Aires en el año 1753, depositado en el Archivo Histórico de Tucumán, el cual se encuentra en muy mal estado de conservación. El mismo sirvió como elemento a favor de los amaychas en el centenario litigio sostenido entre los comuneros y un terrateniente salteño. En base a la importancia del mismo, en cuanto cimienta las pretensiones territoriales de los indios de Amaicha, su contenido ha sido reproducido y analizado por distintos autores pero tomando como base una fuente literaria del siglo XX, produciendo una serie de "copias de copias" que han perpetuado errores. Por ello en este trabajo se ofrece la transcripción textual del testimonio de la cédula inserto en el expediente de su protocolización en el año 1892, con el objetivo fundamental de poner a disposición el texto original de la famosa "Cédula Real" y reducir el margen de errores interpretativos. Por otro lado se hace una sistematización de las diferentes versiones modernas existentes señalando ciertas inconsistencias, y se exponen algunas reflexiones sobre las implicancias espaciales, políticas y sociohistóricas en torno al texto.

\section{INDEX}

Keywords: Indians, Amaicha, territory, politics, Tucumán.

Palabras claves: indios, Amaicha, territorio, política, Tucumán.

\section{AUTHOR}

\section{JORGE SOSA}

Sección de Etnología y Etnografía, Departamento de Antropología. Facultad de Filosofía y Letras. Universidad de Buenos Aires, Argentina

Correo electrónico: jsosa@filo.uba.ar 